\title{
BMJ Open Evaluation of the role of transhepatic flow in postoperative outcomes following major hepatectomy (THEFLOW): study protocol for a single- centre, non-interventional cohort study
}

\author{
Mohammad Golriz, ${ }^{1,2,3}$ Anastasia Lemekhova, ${ }^{1,2,3}$ Elias Khajeh, ${ }^{1,3}$ \\ Omid Ghamarnejad, ${ }^{1,3}$ Mohammed Al-Saeedi, ${ }^{1}$ Oliver Strobel, ${ }^{1,2}$ Thilo Hackert, ${ }^{1,2}$ \\ Beat Müller-Stich, ${ }^{1}$ Martin Schneider, ${ }^{1,2}$ Christoph Berchtold, ${ }^{1}$ Parham Tinoush, ${ }^{4}$ \\ Philipp Mayer, ${ }^{4}$ De-Hua Chang, ${ }^{2,4}$ Karl Heinz Weiss, ${ }^{2,5}$ Katrin Hoffmann, ${ }^{1,2,3}$ \\ Arianeb Mehrabi (D) 1,2,3
}

To cite: Golriz M, Lemekhova A, Khajeh $\mathrm{E}$, et al. Evaluation of the role of transhepatic flow in postoperative outcomes following major hepatectomy (THEFLOW): study protocol for a single-centre, non-interventional cohort study. BMJ Open 2019;9:e029618. doi:10.1136/ bmjopen-2019-029618

- Prepublication history for this paper is available online. To view these files, please visit the journal online (http://dx.doi. org/10.1136/bmjopen-2019029618).

$M G$ and $A L$ contributed equally.

Received 01 February 2019 Revised 02 September 2019 Accepted 03 September 2019

D) Check for updates

(c) Author(s) (or their employer(s)) 2019. Re-use permitted under CC BY-NC. No commercial re-use. See rights and permissions. Published by BMJ.

For numbered affiliations see end of article.

\section{Correspondence to} Professor Arianeb Mehrabi; arianeb.mehrabi@med.uniheidelberg.de

\section{ABSTRACT}

Introduction Liver resection is the only curative treatment for primary and secondary hepatic tumours. Improvements in perioperative preparation of patients and new surgical developments have made complex liver resections possible. However, small for size and flow syndrome (SFSF) is still a challenging issue, rendering patients inoperable and causing postoperative morbidity and mortality. Although the role of transhepatic flow in the postoperative outcome has been shown in small partial liver transplantation and experimental studies of SFSF, this has never been studied in the clinical setting following liver resection. The aim of this study is to systematically evaluate transhepatic flow changes following major liver resection and its correlation with postoperative outcomes. Methods and analysis The TransHEpatic FLOW (THEFLOW) study is a single-centre, non-interventional cohort study, and aims to enrol 50 patients undergoing major hepatectomy (defined as hemihepatectomy or extended hepatectomy based on the Brisbane classification) with or without prior chemotherapy. The portal venous flow, hepatic artery flow and portal venous pressure are measured before and after each resection. All patients are followed-up for 3 months after the operation. During each evaluation, standard clinical data, posthepatectomy liver failure and overall morbidity and mortality will be recorded. THEFLOW study was initiated on 25 March 2018 and is expected to progress for 2 years. Ethics and dissemination This protocol study received approval from the Ethics Committee of the University of Heidelberg (registration number: S576/2017). The results of this study will be published in a peer-reviewed journal, and will also be presented at medical meetings. Trial registration number NCT03762876.

\section{INTRODUCTION}

Liver resection is the only curative treatment for many primary and secondary hepatic tumours. ${ }^{1-3}$ Improvements in patient selection
Strengths and limitations of this study

- The THEFLOW study is a single-centre, noninterventional cohort study.

- The THEFLOW study will be the first prospective clinical study to systematically evaluate the association between transhepatic flow changes and posthepatectomy results.

- Transhepatic haemodynamic changes following liver resection will be assessed in livers with and without prior chemotherapy.

- A limitation of this study is that a postoperative monitoring of the portal vein pressure is not possible.

- Findings of this study may help to improve the postoperative outcomes of patients with a high risk of small for size and flow syndrome.

criteria, surgical methods and postoperative care have made major liver resections (hemihepatectomy or extended hepatectomy) more feasible and safer. ${ }^{4-8}$ However, posthepatectomy liver failure (PHLF) or the risk of developing PHLF because of small remnant liver (as small for size syndrome) still needs novel predictive factors ${ }^{9}{ }^{10}$ and remains challenging because they can render the patient inoperable or cause postoperative mortality and morbidity. ${ }^{11}{ }^{12}$ The current preventive and therapeutic efforts, which focus only on the remnant liver volume (eg, two-staged hepatectomy, portal vein embolisation, or associating liver partition and portal vein ligation for staged hepatectomy (ALPPS)), have improved the results, but they are still not effective enough. ${ }^{13-16}$ Therefore, there are still many patients, who either are not 


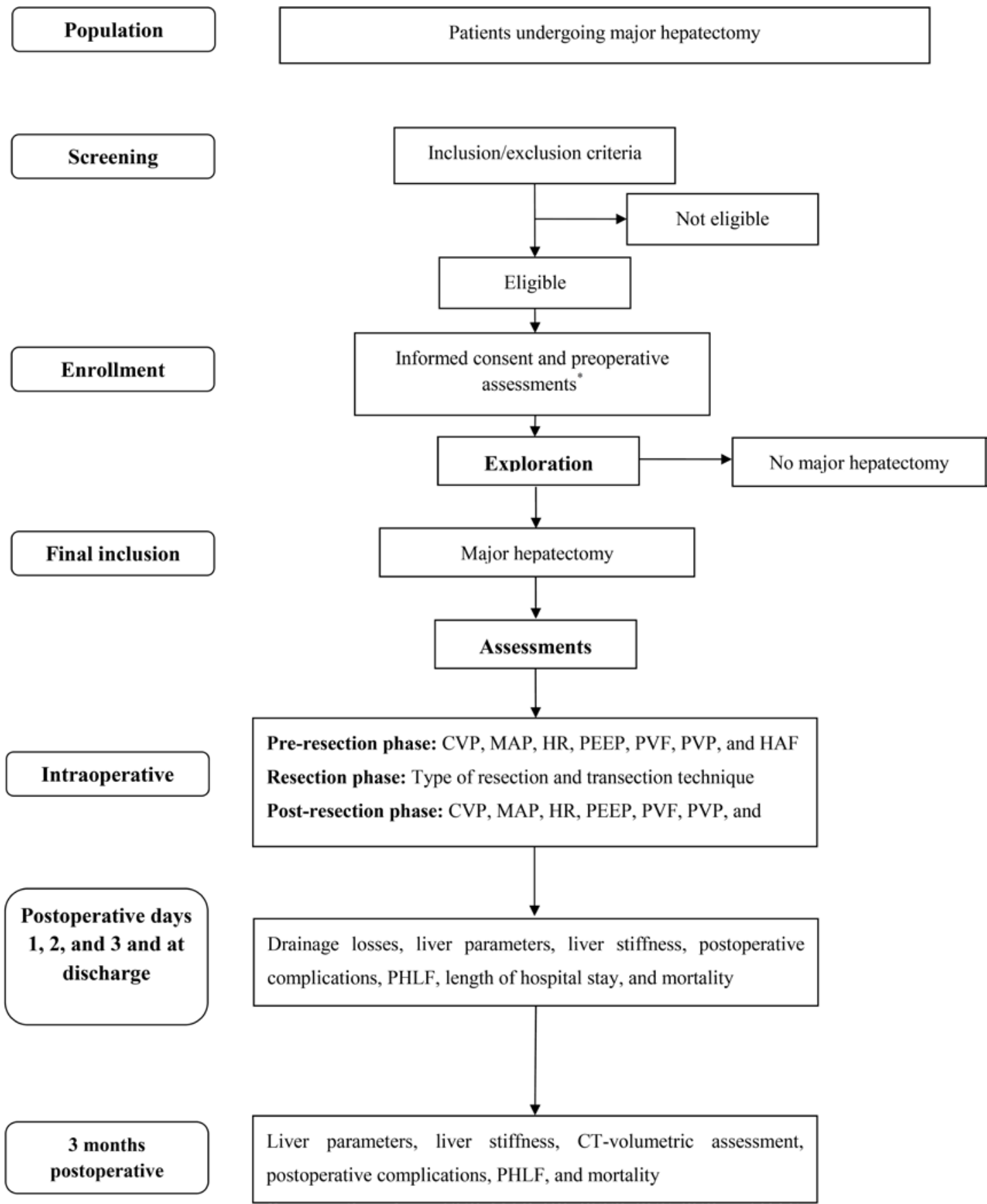

Figure 1 Study design flow chart. *Preoperative assessments: baseline data (eg, date of birth, gender, weight (kg), height (cm), diagnosis, prior treatment (chemotherapy), comorbidities, spleen size), total and future liver volume (measured by CT volumetry), and liver stiffness (measured by fibroscan). CVP, central vein pressure; HAF, hepatic artery flow; MAP, mean arterial pressure; HR, heart rate; PEEP, positive end-expiratory pressure; PHLF, posthepatectomy liver failure; PVF, portal vein flow; PVP, portal vein pressure .

operated because of the high risk of PHLF or suffer from PHLF following major hepatectomy.

Findings from partial liver transplantation have revealed the role of transhepatic flow parallel to the size of the remnant liver ${ }^{17}{ }^{18}$; therefore, the syndrome was discussed to be called as small for size and flow syndrome (SFSF) ${ }^{19-21}$ In an experimental setting, the portal vein flow (PVF) and the portal vein pressure (PVP) increase significantly for the remnant liver volume following major liver resection. ${ }^{22}$ This increase has important pathophysiological consequences, causing cellular necrosis and $\mathrm{SFSF}^{8}{ }^{23-25}$ Troisi $e$ t al suggested an upper limit of $250 \mathrm{~mL} / \mathrm{min} / 100 \mathrm{~g}$ PVF to prevent SFSF after living donor liver transplantation. ${ }^{196}$ Although transhepatic flow plays a role in partial liver transplantation ${ }^{27}$ and in experimental liver resection, ${ }^{22}$ this has never been shown systematically following liver resection in the clinical setting.

The primary aim of this study is to systematically evaluate the amount of changes in transhepatic flow following major liver resection. Furthermore, association 


\section{Box 1 Demographic and baseline data}

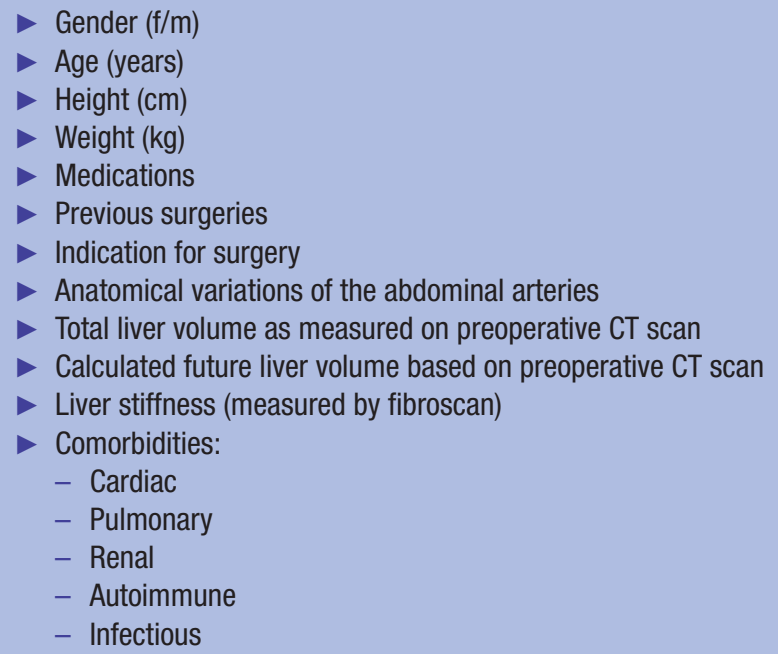

of transhepatic flow with postoperative outcomes such as SFSF will be investigated.

\section{METHODS AND ANALYSIS \\ Study settings}

The THEFLOW study is a single-centre, non-interventional cohort study. The study aims to enrol 50 patients undergoing major liver resection (ie, a hemihepatectomy or an extended hemihepatectomy) with or without prior chemotherapy. This study is taking place at the division of liver surgery in the Department of General, Visceral, and Transplantation Surgery of the University of Heidelberg. Our centre is a referral hepatopancreatobiliary centre that is highly specialised in the treatment of patients with advanced hepatobiliary cancer. It was initiated on 25 March 2018 and is expected to progress for 2 years.

\begin{tabular}{ll}
\hline $\begin{array}{l}\text { Table } 1 \text { Inclusion and exclusion criteria of the THEFLOW } \\
\text { study }\end{array}$ & Exclusion criteria \\
\hline Inclusion criteria & $\begin{array}{l}\text { Previous surgery of the } \\
\text { hepatoduodenal ligament }\end{array}$ \\
\hline Aged above 18 years & $\begin{array}{l}\text { Status after transjugular } \\
\text { intrahepatic portosystemic shunt }\end{array}$ \\
$\begin{array}{l}\text { Undergoing major } \\
\text { hepatectomy }\end{array}$ & Portal vein thrombosis \\
\hline Patient consent & Portal vein hypertension \\
& Vascular malformation \\
& Cirrhosis \\
& $\begin{array}{l}\text { Metabolic liver diseases } \\
\text { Cardiac failure }\end{array}$ \\
& Pulmonary hypertension \\
& Not able to give consent \\
\hline
\end{tabular}

\section{Patient recruitment}

As shown in the study flow chart (figure 1), all patients who undergo major hepatectomy (defined as hemihepatectomy or extended hepatectomy according to the Brisbane nomenclature $)^{28}$ are currently being screened for eligibility. Eligible patients that provide informed consent will be treated and followed up according to routine procedures at the Department of General, Visceral, and Transplantation Surgery in Heidelberg University Hospital. Transhepatic flow and pressure parameters, that is, portal venous flow, hepatic artery flow (HAF) and PVP, will be measured in study participants before and after resection; meanwhile, the standard surgical procedure is not altered. We will look for anatomical variations, stenosis of the celiac trunk or superior mesentery artery, as these factors affect the physiological flow of the liver artery and portal vein. Eligibility will be determined based on informed consent status, age, planned surgery and comorbidities (table 1). Furthermore, total liver volume will be calculated based on preoperative imaging. It is important to note that central tumours may compress the vessels, precluding measurement of physiological flow or pressure. Patients with such tumours will be excluded from the study.

\section{Outcome measures}

After enrolment, demographic and baseline data (box 1) of included patients will be recorded. Participants will be monitored intraoperatively, on postoperative days (PODs) 1, 2, 3 and at discharge. After discharge, patients will be visited on POD 90. As shown in table 2, all intraoperative findings, postoperative complications and laboratory parameters will be recorded intraoperatively, during hospital stay, and on POD 90. To enhance participant retention and to avoid loss to follow-up, we will contact patients during the follow-up period to remind them of scheduled visits and to arrange appointments.

\section{Primary endpoint}

PVF will be measured before and following the liver resection. To assess the predictive role of PVF in SFSF, changes in PVF will be evaluated and stratified based on remnant liver volume (table 3 ).

\section{Secondary endpoint}

Intraoperative outcomes, including vital signs, central vein pressure (CVP), mean arterial pressure (MAP), type of resection, transection technique, intraoperative complications, HAF, PVP, estimated blood loss and operating time, will be reported. To calculate the variation of the transhepatic flow to the remnant liver volume, we will measure the removed liver volume during surgery and use CT volumetric assessment to quantify the liver volume before and 3 months after surgery. Additionally, liver stiffness will be evaluated using fibroscan before surgery, at discharge and 3 months after surgery. Laboratory results (table 4 ), length of hospital stay, postoperative 
Table 2 THEFLOW study design according to the Standard Protocol Items: Recommendations for Interventional Trials checklist

\begin{tabular}{|c|c|c|c|c|c|c|c|}
\hline \multirow[b]{3}{*}{ Time point } & \multicolumn{7}{|c|}{ Study period } \\
\hline & \multirow{2}{*}{$\begin{array}{l}\text { Enrolment } \\
\text { Admission } \\
\text { day }\end{array}$} & \multirow{2}{*}{$\begin{array}{l}\text { Operation } \\
\begin{array}{l}\text { Operation } \\
\text { day }\end{array} \\
\end{array}$} & \multicolumn{2}{|c|}{ Post operation } & \multirow[b]{2}{*}{ POD 3} & \multirow[b]{2}{*}{ Discharge } & \multirow[b]{2}{*}{ POD 90} \\
\hline & & & POD 1 & POD 2 & & & \\
\hline \multicolumn{8}{|l|}{ Enrolment: } \\
\hline Eligibility screen & $\mathrm{x}$ & & & & & & \\
\hline Informed consent & $\mathrm{x}$ & & & & & & \\
\hline Baseline assessments & $\mathrm{x}$ & & & & & & \\
\hline \multicolumn{8}{|l|}{ Assessments: } \\
\hline $\begin{array}{l}\text { Flows (PVF, HAF), pressures (PVP, CVP, and } \\
\text { MAP) and vital signs }\end{array}$ & & $\mathrm{x}$ & & & & & \\
\hline Type of resection and transection technique & & $x$ & & & & & \\
\hline Intraoperative complications & & $x$ & & & & & \\
\hline Estimated blood loss & & $\mathrm{x}$ & & & & & \\
\hline Operating time & & $x$ & & & & & \\
\hline Liver stiffness & $\mathrm{x}$ & & & & & $\mathrm{x}$ & $\mathrm{x}$ \\
\hline CT volumetric assessment & $\mathrm{x}$ & & & & & $x$ & $x$ \\
\hline Length of hospital stay & & & $\mathrm{x}$ & $\mathrm{x}$ & $\mathrm{x}$ & $\mathrm{x}$ & \\
\hline Drainage losses & & & $x$ & $x$ & $x$ & $x$ & \\
\hline Laboratory findings & $\mathrm{x}$ & $x$ & $\mathrm{x}$ & $\mathrm{x}$ & $\mathrm{x}$ & $\mathrm{x}$ & $\mathrm{x}$ \\
\hline Postoperative complications & & & $\mathrm{x}$ & $x$ & $\mathrm{x}$ & $x$ & $x$ \\
\hline PHLF & & & $x$ & $x$ & $x$ & $\mathrm{x}$ & $\mathrm{x}$ \\
\hline Mortality & & $\mathrm{x}$ & $\mathrm{x}$ & $\mathrm{x}$ & $\mathrm{x}$ & $\mathrm{x}$ & $\mathrm{x}$ \\
\hline
\end{tabular}

CVP, central vein pressure; HAF, hepatic artery flow; MAP, mean arterial pressure; PHLF, posthepatectomy liver failure; POD, postoperative day; PVF, portal vein flow; PVP, portal vein pressure.

complications, PHLF and all-cause mortality will also be reported until POD 90 (tables 2 and 3).

\section{Patient and public involvement}

The patients and public were not involved in the planning of this study.

\section{Modification of the protocol}

Protocol amendments will be considered by the principal investigator. All protocol amendments will be submitted to the Ethics Committee for approval. No patients will be recruited until the modifications are accepted.

\section{Methods for minimising bias}

To avoid selection bias and to ensure homogeneity of patients, all patients admitted to Heidelberg University Hospital that are scheduled to undergo major liver resection will be screened for eligibility. Every patient who meets the inclusion criteria and does not meet the exclusion criteria will be informed of the study and included if he/she gives consent to participate (table 1). Data will be analysed after all data have been collected. Furthermore, selective reporting will be avoided by submitting the study protocol prior to data collection including all information concerning study endpoints and statistical analysis.
Any financial relationship and any conflict of interest that may arise will also be declared.

\section{Ethical and legal aspects and termination criteria}

Patients will be informed verbally and in writing about the nature and scope of the planned study and participation in the study will be voluntary. The names of the patients and all other confidential information will be subject to medical confidentiality and the provisions of the Federal Data Protection Act. In accordance with the European General Data Protection Regulations, all patient data will be collected anonymously. For statistical analysis, patient data will only be transferred in anonymised form. Third parties will not have access to original patient records.

Consent to participate may be withdrawn at any time, without giving reasons and without affecting further medical care. On withdrawal from the study, the patient's data will be irreversibly deleted unless they agree to materials and data already collected being used anonymously in evaluation.

\section{Data management}

All data will be collected and recorded in case report forms (CRFs) by an investigator before transfer to the 
Table 3 Primary and secondary endpoints of the THEFLOW study

\begin{tabular}{|c|c|}
\hline Endpoints & Definitions \\
\hline \multicolumn{2}{|l|}{ Primary endpoint } \\
\hline Portal vein flow (PVF) & PVF (mL/min) \\
\hline Portal vein pressure (PVP) & PVP (mm Hg) \\
\hline Hepatic artery flow (HAF) & $\mathrm{HAF}(\mathrm{mL} / \mathrm{min})$ \\
\hline Mean arterial pressure (MAP) & MAP $(\mathrm{mm} \mathrm{Hg})$ \\
\hline Heart rate & Heart rate (beats/min) \\
\hline Positive end-expiratory pressure (PEEP) & $\operatorname{PEEP}\left(\mathrm{cmH}_{2} \mathrm{O}\right)$ \\
\hline $\begin{array}{l}\text { Type of resection and transection } \\
\text { technique }\end{array}$ & Type of resection and transection technique will be documented during the surgery \\
\hline Length of hospital stay & Time (days) from the day of the operation until the day of discharge \\
\hline Liver stiffness & Will be reported according to the fibroscan results \\
\hline CT volumetric assessment & $\begin{array}{l}\text { Total liver volume, future liver remnant volume and liver volume } 3 \text { months after surgery } \\
\text { will be evaluated }\left(\mathrm{cm}^{3}\right)\end{array}$ \\
\hline Drainage losses & The amount $(\mathrm{mL})$ and content of drainage will be evaluated during hospitalisation \\
\hline Laboratory findings & Presented in table 4 \\
\hline Postoperative complications & $\begin{array}{l}\text { Each complication will be reported and graded according to the Clavien-Dindo } \\
\text { classification }\end{array}$ \\
\hline Posthepatectomy liver failure (PHLF) & PHLF rate will be determined based on the ISGLS criteria ${ }^{34}$ \\
\hline
\end{tabular}

ISGLS, International Study Group of Liver Surgery.

\begin{tabular}{|c|c|}
\hline Laboratory findings & Parameters \\
\hline Cholestasis parameters & $\begin{array}{l}\text { Alkalinephosphatase (U/I) and gamma- } \\
\text { glutamyltransferase (U/I) }\end{array}$ \\
\hline Excretion parameters & Bilirubin (mg/dL) \\
\hline Hepatocellular integrity & $\begin{array}{l}\text { Glutamate-oxalacetate-transaminase (U/I), } \\
\text { and glutamate-pyruvate-transaminase } \\
(\mathrm{U} / \mathrm{I})\end{array}$ \\
\hline Synthesis parameters & $\begin{array}{l}\text { Albumin }(\mathrm{g} / \mathrm{L}) \text { and international normalized } \\
\text { ratio (INR) }\end{array}$ \\
\hline Tumour markers & $\begin{array}{l}\text { Alpha fetoprotein }(\mathrm{ng} / \mathrm{mL}) \text {, } \\
\text { carcinoembryonic antigen }(\mu \mathrm{g} / \mathrm{L}) \text {, and } \\
\text { carbohydrate antigen } 19-9(\mathrm{U} / \mathrm{mL})\end{array}$ \\
\hline Infection parameters & $\begin{array}{l}\text { Leucocytes }(/ \mathrm{nL}), \text { C reactive protein }(\mathrm{mg} / \mathrm{L}) \\
\text { and procalcitonin }(\mathrm{ng} / \mathrm{mL})\end{array}$ \\
\hline $\begin{array}{l}\text { Cardiovascular } \\
\text { parameters }\end{array}$ & $\begin{array}{l}\text { Blood pressure, pulse, haemoglobin ( } g / d \mathrm{~d}) \\
\text { and haematocrit }(\mathrm{l} / \mathrm{l})\end{array}$ \\
\hline Electrolytes & $\begin{array}{l}\text { Sodium }(\mathrm{mmol} / \mathrm{L}) \text {, potassium }(\mathrm{mmol} / \mathrm{L}) \text { and } \\
\text { calcium }(\mathrm{mmol} / \mathrm{L})\end{array}$ \\
\hline Kidney function & $\begin{array}{l}\text { Creatinine }(\mathrm{mg} / \mathrm{dL}) \text { and glomerular } \\
\text { filtration rate }\end{array}$ \\
\hline Pancreatic enzymes & Amylase (U/I) (pancreatic) and lipase (U/I) \\
\hline
\end{tabular}

data management centre. To ensure accurate data collection, the CRF will be completed by an investigator who did not evaluate the patient after each patient visit. All demographic and baseline clinical data, as well as primary and secondary outcome measures, will be recorded in the CRF. All data will be checked, and any missing data will be obtained from the trial database or from participants. To ensure patient confidentiality, the CRF for each patient will be given an anonymous allocation number. We will ask for permission to continue follow-up and data collection in the event of withdrawal from the study. The principal investigator will review and sign all completed CRFs.

\section{Statistical design and analysis}

Sample size

This is an explorative study; therefore, a formal sample size was not calculated. Transhepatic flow changes will be measured in 50 patients, which is considered sufficient.

\section{Statistical analysis}

Wilcoxon signed-rank test will be used to compare paired variables (ie, PVF, PVP, HAF, CVP, MAP and heart rate) before and after liver resection. Continuous variables will be compared between two groups using Mann-Whitney 
$\mathrm{U}$ test. The association of categorical variables will be evaluated by Fisher's exact test. To assess the predictive role of transhepatic flow changes, multivariate logistic regression analyses with forward stepwise selection will be performed. Variables with $\mathrm{p}<0.1$ from the univariate analysis will be included in the multivariate logistic regression analysis. The significance level will be set at $\alpha \leq 0.05$, representing 95\% CI.

\section{DISCUSSION}

Despite numerous new surgical achievements, SFSF remains a challenging risk for patients who have to undergo major liver resection. ${ }^{19}$ Patients with marginal remnant liver volume are particularly at risk and as a result, these patients are often considered inoperable or develop postoperative SFSF. To overcome this problem and prevent PHLF, efforts have been made to give the remnant liver time to regenerate after resection, such as in two-staged hepatectomy, portal vein embolisation and ALPPS. ${ }^{29} 30$ However, despite promising primary results, complications remain high and dropouts due to inadequate liver regeneration are often, meaning many patients cannot be operated on further. ${ }^{30}$ During the last years, findings from partial liver transplantation ${ }^{31}$ have highlighted the important role of transhepatic flow in major liver resection. ${ }^{19}$ This important role was confirmed by experimental studies. ${ }^{22}$ In our previous experimental study, major liver resection increased the PVF and PVP for the remnant liver volume. ${ }^{22}$ This was particularly significant after extended liver resection. The high PVF and PVP put too much pressure on the parenchyma, causing sinus endothelial damage through high shear stress. This leads to haemorrhage, cellular damage and production of reactive oxygen species ${ }^{32}$ meaning the remnant liver volume fails to function properly.

Although there are many clinical transplantation studies and experimental studies, to the best of our knowledge, there is still no clinical study evaluating transhepatic flow changes and their association with PHLF following major liver resection. Moreover, transhepatic flow and pressure variation have not been compared between the normal liver and a liver after chemotherapy. The THEFLOW study will be the first study to systematically evaluate transhepatic haemodynamic changes in normal and postchemotherapy livers following major hepatectomy. Furthermore, the correlation of the transhepatic flow changes with postoperative outcomes will be evaluated. Findings of the THEFLOW study will define cut-off values for the PVF and PVP that can predict the risk of SFSF in patients undergoing major hepatectomy. Patients with marginal remnant liver volume and/or a haemodynamic risk of SFSF may benefit from a different surgical strategy, for example, adjustment from a one-step to a two-step concept.

In summary, the association between transhepatic flow changes and SFSF after major hepatectomy has not been well investigated. The THEFLOW study will be the first prospective clinical study to systematically evaluate the role of transhepatic flow changes in prediction of SFSF after major hepatectomy. The comprehensive findings of this study may show that the postoperative outcomes of patients with a high risk of SFSF can be improved by adjusting the surgical strategy and by providing more intensive perioperative care.

\section{Trials status}

The THEFLOW study is currently recruiting participants.

\section{Author affiliations}

${ }^{1}$ Department of General, Visceral, and Transplantation Surgery, University of Heidelberg, Heidelberg, Germany

${ }^{2}$ Liver Cancer Center Heidelberg, University of Heidelberg, Heidelberg, Germany

${ }^{3}$ Division of Liver Surgery at Department of General, Visceral, and Transplantation

Surgery, University of Heidelberg, Heidelberg, Germany

${ }^{4}$ Department of Diagnostic and Interventional Radiology, University Hospital Heidelberg, Heidelberg, Germany

${ }^{5}$ Department of Gastroenterology and Hepatology, University of Heidelberg, Heidelberg, Germany

Correction notice This article was previously published with an error. Author name Hackert Thilo should be Thilo Hackert.

Contributors AM, MG and AL developed the original concept of the trial. AM, MG, AL, MA-S and OS developed the design and methodology. MG, AL, EK and OG performed the statistical assessments and developed the analysis plan. MG, $A L$, EK, OG, MA-S, CB, PT and PM contributed to drafting the protocol of the paper and the article. OS, TH, BM-S, MS, CB, PM, D-HC, KHW, KH and AM contributed to the revision of the final report. All authors read and approved the final manuscript.

Funding The authors have not declared a specific grant for this research from any funding agency in the public, commercial or not-for-profit sectors.

Competing interests None declared.

Patient consent for publication Obtained.

Ethics approval This protocol study received approval from the Ethics Committee of the University of Heidelberg (registration number: S576/2017).

Provenance and peer review Not commissioned; externally peer reviewed.

Open access This is an open access article distributed in accordance with the Creative Commons Attribution Non Commercial (CC BY-NC 4.0) license, which permits others to distribute, remix, adapt, build upon this work non-commercially, and license their derivative works on different terms, provided the original work is properly cited, appropriate credit is given, any changes made indicated, and the use is non-commercial. See: http://creativecommons.org/licenses/by-nc/4.0/.

ORCID iD

Arianeb Mehrabi http://orcid.org/0000-0001-6163-1525

\section{REFERENCES}

1 El-Serag HB, Marrero JA, Rudolph L, et al. Diagnosis and treatment of hepatocellular carcinoma. Gastroenterology 2008;134:1752-63.

2 Manfredi S, Lepage C, Hatem C, et al. Epidemiology and management of liver metastases from colorectal cancer. Ann Surg 2006;244:254-9.

3 Poon RT, Fan ST, Lo CM, et al. Improving survival results after resection of hepatocellular carcinoma: a prospective study of 377 patients over 10 years. Ann Surg 2001;234:63-70.

4 Abdalla EK, Barnett CC, Doherty D, et al. Extended hepatectomy in patients with hepatobiliary malignancies with and without preoperative portal vein embolization. Arch Surg 2002;137:675-80. discussion 80-1.

5 Belghiti J, Hiramatsu K, Benoist S, et al. Seven hundred Forty-seven hepatectomies in the 1990s: an update to evaluate the actual risk of liver resection. J Am Coll Surg 2000;191:38-46.

6 Rahbari NN, Elbers H, Koch M, et al. Randomized clinical trial of stapler versus clamp-crushing transection in elective liver resection. Br J Surg 2014;101:200-7. 
7 Fritzmann J, Kirchberg J, Sturm D, et al. Randomized clinical trial of stapler hepatectomy versus LigaSure ${ }^{\mathrm{TM}}$ transection in elective hepatic resection. Br J Surg 2018;105:1119-27.

8 Rahbari NN, Koch M, Zimmermann JB, et al. Infrahepatic inferior vena cava clamping for reduction of central venous pressure and blood loss during hepatic resection: a randomized controlled trial. Ann Surg 2011;253:1102-10.

9 Mehrabi A, Golriz M, Khajeh E, et al. Meta-analysis of the prognostic role of perioperative platelet count in posthepatectomy liver failure and mortality. Br J Surg 2018;105:1254-61.

10 Golriz M, Ghamarnejad O, Khajeh E, et al. Preoperative thrombocytopenia may predict poor surgical outcome after extended hepatectomy. Can J Gastroenterol Hepatol 2018;2018:1275720:1-11.

11 Shoup M, Gonen M, D'Angelica M, et al. Volumetric analysis predicts hepatic dysfunction in patients undergoing major liver resection. $J$ Gastrointest Surg 2003;7:325-30.

12 Ren Z, Xu Y, Zhu S. Indocyanine green retention test avoiding liver failure after hepatectomy for hepatolithiasis. Hepatogastroenterology 2012;59:782-4.

13 Schadde E, Raptis DA, Schnitzbauer AA, et al. Prediction of mortality after ALPPS Stage-1: an analysis of 320 patients from the International ALPPS registry. Ann Surg 2015;262:780-5. discussion 85-6.

14 Wanis KN, Buac S, Linecker M, et al. Patient survival after simultaneous ALPPS and colorectal resection. World J Surg 2017;41:1119-25.

15 Schadde E, Ardiles V, Robles-Campos R, et al. Early survival and safety of ALPPS: first report of the International ALPPS registry. Ann Surg 2014;260:829-36. discussion 36-8.

16 Kremer M, Manzini G, Hristov B, et al. Impact of neoadjuvant chemotherapy on hypertrophy of the future liver remnant after associating liver partition and portal vein ligation for staged hepatectomy. J Am Coll Surg 2015;221:717-28.

17 Asencio JM, Vaquero J, Olmedilla L, et al. 'Small-for-flow' syndrome: shifting the 'size' paradigm. Med Hypotheses 2013;80:573-7.

18 Vasavada BB, Chen CL, Zakaria M. Portal flow is the main predictor of early graft dysfunction regardless of the GRWR status in living donor liver transplantation - a retrospective analysis of 134 patients. Int J Surg 2014;12:177-80.

19 Golriz M, Majlesara A, El Sakka S, et al. Small for size and flow (SFSF) syndrome: an alternative description for posthepatectomy liver failure. Clin Res Hepatol Gastroenterol 2016;40:267-275.

20 Guglielmi A, Ruzzenente A, Conci S, et al. How much remnant is enough in liver resection? Dig Surg 2012;29:6-17.
21 Golriz M, Ashrafi M, Khajeh E, et al. Establishing a porcine model of small for size syndrome following liver resection. Can J Gastroenterol Hepatol 2017;2017:5127178:1-8.

22 Golriz M, El Sakka S, Majlesara A, et al. Hepatic hemodynamic changes following stepwise liver resection. J Gastrointest Surg 2016;20:587-94.

23 Kelly DM, Demetris AJ, Fung JJ, et al. Porcine partial liver transplantation: a novel model of the 'small-for-size' liver graft. Liver Transpl 2004;10:253-63.

24 Man K, Fan S-T, Lo C-M, et al. Graft injury in relation to graft size in right lobe live donor liver transplantation: a study of hepatic sinusoidal injury in correlation with portal hemodynamics and intragraft gene expression. Ann Surg 2003;237:256-64.

25 Nagino M, Ando M, Kamiya J, et al. Liver regeneration after major hepatectomy for biliary cancer. Br J Surg 2001;88:1084-91.

26 Troisi R, de Hemptinne B. Clinical relevance of adapting portal vein flow in living donor liver transplantation in adult patients. Liver Transp/ 2003;9:S36-S41.

27 Troisi Rl, Berardi G, Tomassini F, et al. Graft inflow modulation in adult-to-adult living donor liver transplantation: a systematic review. Transplant Rev (Orlando) 2017;31:127-35.

28 Pang YY. The Brisbane 2000 terminology of liver anatomy and resections. HPB 2000; 2:333-39. HPB (Oxford) 2002;4:99-100. author reply.

29 Vivarelli M, Vincenzi P, Montalti R, et al. ALPPS procedure for extended liver resections: a single centre experience and a systematic review. PLoS One 2015;10:e0144019.

30 Schnitzbauer AA. A comparison of pitfalls after ALPPS stage 1 or portal vein embolization in Small-for-Size setting hepatectomies. Visc Med 2017;33:435-41.

31 Troisi R, Ricciardi S, Smeets $\mathrm{P}$, et al. Effects of hemi-portocaval shunts for inflow modulation on the outcome of small-for-size grafts in living donor liver transplantation. Am J Transplant 2005;5:1397-404.

32 Serenari $M$, Cescon $M$, Cucchetti $A$, et al. Liver function impairment in liver transplantation and after extended hepatectomy. World $\mathrm{J}$ Gastroenterol 2013;19:7922-9.

33 Clavien PA, Barkun J, de Oliveira ML, et al. The Clavien-Dindo classification of surgical complications: five-year experience. Ann Surg 2009;250:187-96.

34 Rahbari NN, Garden OJ, Padbury R, et al. Posthepatectomy liver failure: a definition and grading by the International Study group of liver surgery (ISGLS). Surgery 2011;149:713-24. 